BULLETIN Bulletin hispanique

HispaniquE Université Michel de Montaigne Bordeaux

$115-2$ | 2013

Les traductions vieillissent-elles?

\title{
Contribució de les traduccions catalanes de Verne a la fixació d'un model narratiu i lingüístic
}

Rosa Elias, primera traductora verniana de la postguerra

\section{Eusebi Coromina Pou}

\section{(2) OpenEdition}

\section{Journals}

Electronic version

URL: http://journals.openedition.org/bulletinhispanique/2887

DOI: 10.4000/bulletinhispanique.2887

ISSN: 1775-3821

\section{Publisher}

Presses universitaires de Bordeaux

Printed version

Date of publication: 28 December 2013

Number of pages: $685-696$

ISBN: 978-2-86781-908-7

ISSN: 0007-4640

Electronic reference

Eusebi Coromina Pou, «Contribució de les traduccions catalanes de Verne a la fixació d'un model narratiu i lingüístic », Bulletin hispanique [Online], 115-2 | 2013, Online since 14 February 2017, connection on 02 May 2019. URL : http://journals.openedition.org/bulletinhispanique/2887 ; DOI 10.4000/bulletinhispanique.2887 


\title{
Contribució de les traduccions catalanes de Verne a la fixació d'un model narratiu i lingüístic Rosa Elias, primera traductora verniana de la postguerra ${ }^{1}$
}

\author{
Eusebi Coromina Pou \\ Universitat de Vic
}

Divers mouvements favorisent, à la charnière du XIX et du XXe siècle, la traduction en catalan d'ouvrages appartenant à la littérature universelle afin de trouver, à travers la pratique de la traduction, un canon littéraire propre. Les nombreuses traductions de Jules Verne, parmi lesquelles il convient de souligner celles de Rosa Elias, ont définitivement contribué à la fixation d'un nouveau modèle narratif et linguistique catalan.

Mots-clés : histoire de la traduction, canon littéraire, Jules Verne traduit en catalan, Rosa Elias.

Distintos movimientos promueven, a caballo entre los siglos XIX y XX, la traducción al catalán de obras de la literatura universal a fin de forjar, a través de la práctica traductora, un canon literario propio. Las numerosas traducciones de Jules Verne, de las que destacan las realizadas por Rosa Elias, contribuyen decisivamente a la fijación de un nuevo modelo narrativo y lingüistico catalán.

Palabras clave: historia de la traducción, canon literario narrativo, Jules Verne traducido al catalán, Rosa Elias.

At the turn of the twentieth century, various movements promoted the translation of world literature into Catalan with the aim of establishing, through the practice of translation, a proper literary canon in Catalan. Many translations of Jules Verne, among which those of Rosa Elias are particularly noteworthy, decisively contribute to fix a new narrative and linguistic model in Catalan.

Keywords: history of translation, narrative literary canon, Jules Verne tranlated into Catalan, Rosa Elias.

1. Aquest article s'inscriu en el grup d'investigació consolidat «Estudis de gènere: traducció, literatura, història i comunicació» (GETLIHC) de la Universitat de Vic (AGAUR, SGR-833) i en el subprojecte I+D «Traductoras y traducciones en la Cataluńa contemporánea (1939-2000)» (Ref.: FFI2010-19851-C02-02), finançat pel Ministerio de Ciencia e Innovación. 
G 1 principal objectiu del noucentisme, al primer terç del XX, era la consecució C d'una llengua comuna, moderna i codificada, útil especialment per als usos elevats. Fabra ja treballava en aquesta empresa lingüística, però calia a més un cànon literari, especialment narratiu, al qual es pogués aplicar el model lingüístic que s'estava codificant. Així, hom creia útil promoure la traducció de la literatura universal a fi de trobar, a la llum de la pràctica traductora, un model literari propi, dúctil i una llengua neta de calcs de l'espanyol, tal com sosté Malé (2007).

\section{La tasca d'Editorial Catalana i de Josep Carner}

Enric Prat de la Riba, president de la Mancomunitat de Catalunya, en el seu afany de dotar el país d'infraestructures culturals, en colllaboració amb persones de les més variades tendències, comptà amb Josep Carner, impulsor del noucentisme literari, l'ideòleg del qual, Eugeni d'Ors, n'havia encunyat la denominació el 1906 des del seu Glosari a La Veu De Catalunya. Carner fou el primer director literari d'Editorial Catalana, en la qual va signar 16 traduccions dins la col-lecció Biblioteca Literària. La col-lecció va arribar a publicar 118 títols entre 1918 i 1931. Inclö̈a principalment traduccions de narrativa, fetes per Josep Carner -el més prolífic-, Carles Riba (hi publicà la primera edició de L'Odissea), Llorenç Riber, Joaquim Ruyra, Rodolf J. Slaby, Marià Manent, M. Antònia Salvà, Emili Vallès, Tomàs Garcés, Carles Soldevila o Rafel Marquina.

Murgades (1994) i després Ortín (2004) destaquen les tres "grans raons» de la preeminència atorgada pels noucentistes a les traduccions. D'una banda, la traducció de textos literaris podia ajudar a conformar un català apte per a usos elevats. De l'altra, podia contribuir a refer el pont entre la literatura medieval i la modernitat, tot superant el fossat dels segles de decadència literària o de repressió. Finalment, les traduccions representaven la superació del localisme, i acostaven la identitat lingüístico-cultural pròpia a la cultura universal.

\section{El MOdel NOUCENTISTA}

La reconstrucció d'una tradició culta i/o literària estroncada en diversos períodes va donar com a resultat el model noucentista, sovint -no sempreartificiós, amb la reducció dels registres a un d'estil formal ornamental i pompós, especialment xocant en la prosa narrativa que reflectia situacions quotidianes, a causa del seu allunyament de la llengua viva, com han remarcat Pericay i Toutain (1996). L'estil noucentista, amb les seves bondats i defectes, va persistir -com una taula de salvament de vegades- en traduccions de fins ben entrada la segona meitat del XX.

Mallafrè (2000: 10) valora Carner i el justifica de les possibles inadequacions estilístiques, pel fet que pertanyia, diu, a «una època que no va tenir una continuïtat ni una evolució gradual normals». 
El fet que nombroses traduccions del primer terç del XX no haguessin obtingut resultats satisfactoris o no haguessin assolit l'estatus de traduccions intemporals, probablement es devia a la dèria de voler trobar en la tasca traductora solució a la majoria de problemes de la llengua d'arribada i alhora d'experimentar-hi. De fet, cada original té una identitat, una personalitat-que no s'hauria de perdre en la traducció-, imposada per l'autor, per la llengua i per l'estil de l'obra. Com indica Mallafrè (2000: 14-15): «No és la tasca del traductor preocupar-se de l'enriquiment de la pròpia llengua. Naturalment, com més madura sigui la llengua d'arribada i en la mesura que sigui capaç de naturalitzar d'una manera versemblant l'expressió de l'autor, en principi aliena, més se'n sortirà.»

\section{TRADUCCIONS MODÈLIQUES}

Sorgiren, però, traduccions modèliques. A més de les dels clàssics grecollatins de la col-lecció Bernat Metge (la primera traducció és del 1923) o de les de la Fundació Bíblica Catalana (que entre 1928-1948 traduí la Bíblia)2 ${ }^{2}$ hi hagué la traducció de l'Odissea d'Homer, per Riba (la primera, del 1919, en 3 vols a Editorial Catalana) -de les quals s'ha ocupat Parcerisas (2009)-, o bé la de Pickwick, de Dickens, per Carner (en 3 volums a Proa l'any 1931) i, ja a la postguerra, la de Romeo i Julieta, de Shakespeare, per Sagarra (publicada el 1959 a Alpha). Hi hagué, evidentment, models de llengua i concepcions estilístiques altres que els noucentistes, encarnats pel mateix Sagarra, Foix, Pla, Tasis, Soldevila, Rovira i Virgili, Rodoreda, etc., que contribuïren a fixar un llenguatge literari català genuí, flexible, més acostat a la llengua viva quan feia falta.

Qualsevol traductor -però també qualsevol escriptor- acaba configurant el cabal de l'estil personal combinant els coneixements de la tradició de la pròpia llengua amb els que obté traduint o llegint altres llengües $i$, alhora, a partir dels actes comunicatius que manté en l'àmbit familiar i en els cercles socials més propers, en una època determinada.

En aquest sentit, Mallafrè, autor de la magnífica traducció d'Ulisses, de Joyce ${ }^{3}$, que és un compendi dels problemes que pot arribar a presentar una traducció literària, diu que traduint Fielding, Beckett, Sterne o Joyce li venien solucions sentides al seu germà gran, $\mathrm{o} a \mathrm{l}$ mercat de Reus (confluència de girs dialectals, d'argot de gitanos), sentides a una tia monja o bé durant les vacances d'estiu (Mallafrè 1999: 12). Al costat de les lectures escolars en castellà, va aprendre a llegir-diu-amb En Patufet (1904-1938) d'abans de la guerra, o amb les «Pàgines viscudes», de Josep M. Folch i Torres, revista i autor que, havent

2. Aquestes dues empreses culturals van comptar amb el mecenatge de Francesc Cambó (Verges, Baix Empordà 1876 - Buenos Aires 1947), polític, advocat i financer.

3. La primera edició de la traducció fou publicada el 1981 a Leteradura; el 1990 fou reeditada per Edhasa, i, finalment, el 1996 n’aparegué la versió revisada a Proa. 
adoptat la normativa fabriana, van divulgar un model de llenguatge literari nou, d'acceptació general, en què la parla i l'escriptura no estaven divorciades. Malgrat l'escola de la seva època, Mallafrè (nascut a Reus el 1941), com altres traductors i traductores, coneixia o sabia de memòria, perquè li havien arribat, versos i fragments de textos de Verdaguer, de Pitarra, de Sagarra, dels Pastorets (en la versió de Folch i Torres), de la Passió, etc.

\section{La influència de Jules Verne en Folch i Torres}

Llegit per diverses generacions de la primera meitat del XX, i més enllà, Folch i Torres (Barcelona, 1880-1950) és un dels escriptors que rep plenament la influència de Jules Verne. Com veurem, Verne forní a Folch i Torres uns models narratius i literaris, tal com ha posat en relleu Pérez Vallverdú (2005), que s'adaptaven als clàssics de la literatura d'aventures, a la literatura infantil i juvenil i també a les exigències editorials i comercials de Josep Baguñà.

Jules Verne (Nantes 1828 - Amiens 1905) arriba d'hora a Catalunya: el 1866 el Diario de Barcelona en publica en forma de fulletó De la Tierra a la Luna, i el 1872 i 1879 s'estrenen amb èxit a Barcelona sengles espectacles musicals que en parodien obres: De San Pol al Polo Nort i De la Terra al Sol. No és, però, fins als anys 20 del segle $\mathrm{XX}$ que Verne és traduït al català.

Entre 1863 i 1905 l'autor francès, en vida, havia publicat 61 novel.les (i 13 de pòstumes entre 1905 i 1910), que esdevindrien clàssics d'aventures, de ciència-ficció o d'anticipació de ciència-ficció. De tota manera, a la Catalunya vuitcentista se'n van llegir les versions en castellà, publicades a la Biblioteca Ilustrada de Gaspar y Roig i a l'editorial de Sáenz Jubera, també de Madrid, tal com ha estudiat Pinyol (2005: 18), el qual assenyala:

«Resulta significatiu que les grans publicacions literàries en català del darrer terç del segle XIX -La Renaixensa, Lo Gay Saber i L'Avenç- no publiquin cap text de l'escriptor francès i que ni tan sols hi sigui objecte del més petit comentari. Fa la impressió que, entre la crítica i els escriptors que conreaven literatura culta, Verne estava catalogat com a autor de literatura de consum en els gèneres d'aventures i fantàstic.»

Però Serrafina (1903: 3) deia de Verne a la revista modernista Pèl \& Ploma: "Universalment conegut per les seves obres de descobriments impossibles, que si bé han distret a molts adolescents de ser advocats o metges, que ja és una gran cosa, deu tenir el remordiment d'haver produït un excessiu planter d'enginyers més somniadors que pràctics.» Amb motiu de la mort de l'escriptor dos anys després d'aquest comentari, Joventut, revista també modernista, en publicava una nota necrològica de to més positiu.

Com dèiem, Folch i Torres troba en Jules Verne una font d'inspiració: hi reconeix un model narratiu modernitzador que impregnarà la seva obra. Alhora, Folch i Torres troba en Fabra un model de llengua flexible, nou, que aprofita tant com pot els materials que li ofereix la llengua real dels seus contemporanis, prèviament depurada. El 1911 Folch i Torres publica El gegant dels aires (a 
la Biblioteca Patufet) tot inaugurant el gènere de la novel.la d'aventures a la literatura catalana adreçada a infants i joves, però llegida també per adults. La novel.la d'aventures, caracteritzada per l'acció, els perills a què s'enfronten els herois, pels ambients exòtics o llunyans i per un ritme narratiu ràpid, sovint $a m b$ una funció d'instrucció pedagògica, no va arribar a tenir en català una col-lecció específica; restava diluïda en col-leccions generalistes o adreçades més o menys explícitament a joves.

El gegant dels aires s'acostava tant a Verne, que aquesta novel.la de Folch i Torres era presentada com una adaptació. La història se situa al Transvaal, on el protagonista, un enginyer català, descobreix el secret del moviment continu i l'aplica a la construcció d'un aparell volador de motor. Paral-lelament, l'obra inclou una bona dosi d'informació geogràfica i referències a la fauna i a la flora de diversos països.

La segona novel.la netament verniana de Folch i Torres, publicada en dos volums el 1913 i el 1914, també a la Biblioteca Patufet, és La família del capità Delmar i Els fills de capità Delmar al Pol. L'obra, amb un títol i un contingut que recorda Les Enfants du capitaine Grant, de Verne (publicada en tres etapes: 186667-68), ja s'inclina més pel model de literatura de descobriments geogràtics i d'aventura heroica, com era palès també en la novel.la folchitorriana d'èxit, del 1910, Aventures extraordinàries d'en Massagran.

No s'ha de negligir la tasca de Josep Baguñà com a editor i propietari de la revista En Patufet, la primera revista infantil en català profusament il.lustrada ${ }^{4}$. Editorial Baguñà, amb les seves col-leccions annexes, assolí una extraordinària difusió, fet que comportà l'expansió d'un model de llengua i de narrativa nous. Folch i Torres hi contribuí de manera destacada. Escriví per a En Patufet des del 1915 fins al 1938, en la qual publicava periòdicament una historieta sota el títol de «Pàgines viscudes», de gran èxit, que reflectia escenes de la vida quotidiana, amb una lliçó moral i de ressonàncies dickensianes, amb infants sotmesos a situacions de penúria i a conflictes familiars.

La inspiració verniana és ben evident també en altres escriptors catalans; per exemple, en el relat de nàufrags titulat justament "Juli Verne», del periodista, pintor, autor teatral i humorista Àngel Ferran i Corominas (Palafrugell 1892 - Tolosa de Llenguadoc, 1971), publicat el 1924 (a Els Contistes Catalans), en què es fa una paròdia de Lilla misteriosa. O bé el relat «La meva estada al centre de la Terra» dins El primer arlequi, de Pere Calders (publicat l'any 1936 a Quaderns Literaris). En la versió caldersiana del Viatge al centre de la Terra, de la qual s'ocupa Gregori (2006), en comptes de tractar-se d'una expedició que vol explorar les interioritats del planeta, els protagonistes cauen accidentalment per un forat a les entranyes de la Terra i en cerquen el lloc de sortida.

4. Va passar de 900 exemplars al primer número, el 1904, a la fabulosa xifra de 60.000 exemplars setmanals el 1926. 


\section{Primeres traduccions de Verne al català}

No és, però, fins al 1926 que Verne és traduït al català. Ho fa Editorial Mentora, filial de Joventut. Mentora, roman activa fins al 1933, quan es fon amb Joventut. Constitueix el primer intent d'oferir literatura popular, més o menys refinada, a un públic mitjà, tal com ha remarcat Molas (1988). Així, a la col-lecció Llibres per a Nois i Jovenets, s’hi edita el 1926 La volta al món en vuitanta dies, traduïda per Clovis Eimeric, pseudònim del periodista, novel.lista i autor dramàtic Lluís Almerich i Sellarès (Barcelona 1882 - 1952). Mentora publicà un any més tard, a la mateixa col-lecció de la primera traducció, $\mathrm{La}$ illa misteriosa, signada amb les inicials J. R. E., d'identitat desconeguda encara avui.

La tercera traducció verniana d'abans de la Guerra Civil fou Miquel Strogoff, el 1930, deguda a J. Bigordà i publicada a la Biblioteca Popular Catalana. Les múltiples traduccions i retraduccions posteriors no van poder començar fins vint anys després d'acabada la Guerra Civil, a partir del 1958 (gràcies al fet, probablement, que l'obra de l'escriptor francès no era sospitosa de subversió).

\section{Rosa Elias obre el CAMÍ DE POSTGUerRa}

El 1958 l'editor Miquel Arimany publica, doncs, La volta al món en vuitanta dies, traduïda per Rosa Elias, que també versiona Viatge al centre de la Terra i De la Terra a la Lluna, publicades aquestes dues un any després, a la mateixa col.lecció que la primera, a la Sant Jordi, adreçada a joves, on apareixerà una altra obra de Verne, Al voltant de la Lluna (1963), en versió de Lluís Gassó i Enric Massó.

Als anys $60 \mathrm{i} 70$ continuen sense estridències les traduccions de Verne, gràcies a Selecta, Bruguera, Laia o El Mall. Però és a partir dels anys 80, especialment amb la incorporació del català a l'ensenyament obligatori, que hi ha la gran eclosió verniana: se'n publiquen més de seixanta traduccions, d'una trentena de títols diferents i a 30 editorials: Barcanova, La Magrana, Bromera, Cruïlla, Edicions 62, La Galera, Drac, Vicens Vives, Joventut, Alfaguara, Beascoa, Castellnou, Eumo Editorial, Lumen, Destino, Pòrtic, Grafalco, Laertes, Laia, Planeta, Edicions Guineu, Club Editor, Columna, Edebé, Punt 17, Edicions del 1984, Pagès Editors, Diputació de Barcelona, L'Atzar i Belinchon Amos.

\subsection{Viatge al centre de la Terra}

Verne en català es féu sentir, com hem dit, des del primer terç del XX coincidint amb el projecte noucentista de bastir, amb el suport de les traduccions, uns models de llengua i de narrativa literària nous, genuïns però connectats amb models europeus, principalment. I una de les obres de Verne amb més èxit ha estat el Viatge al centre de la Terra, en francès publicat el 1864 (ampliat en dos 
capítols el 1967). És la primera narració de viatges i alhora de ciència-ficció, la segona més traduïda al català (vuit traduccions diferents), després de La volta al món en vuitanta dies (deu traduccions diferents). Al Viatge al centre de la Terra, el geòleg i naturalista alemany Otto Lidenbrock descobreix un vell manuscrit rúnic que revela l'indret per on es podia entrar a les entranyes de la Terra. Amb el nebot, Axel -el narrador de la història-, i un guia, Hans, emprenen el viatge al centre del planeta entrant-hi per un volcà islandès apagat. La novel.la, una mescla de dades científiques, d'extrapolacions agosarades i aventures, combina la criptologia, l'espeleologia, la paleontologia, la mineralogia, la follia, el fantàstic amb el viatge. Verne no posseïa uns coneixements científics profunds. Era, com diu Riera Tuèbols (2005: 25), «un diletant en diverses àrees de la ciència. Diletantisme, això sí, que el menaria a poder estar al dia en nombroses qüestions que s'exposen i es desenvolupen en les seves novel.les».

\subsection{La descoberta de Rosa Elias}

La recerca sobre la primera d'aquestes quatre traduccions del Viatge, obra de Rosa Elias (Miquel Arimany Editor, 1959), m’ha permès de descobrir la personalitat d'una traductora ja desapareguda, que es va exiliar a París i a Nova York, i que avui és pràcticament ignorada. Les altres tres traduccions del Viatge que he seleccionat són obra de Joan Valls, poeta i narrador (Barcelona 1901-1991), publicada a L'Atzar el 1982, que va traduir 25 títols d'autors europeus, d'entre els quals destaquen vuit obres de Verne; de Jordi Vidal Tubau (La Galera, 2003), traductor al català i a l'espanyol de més de 150 obres, especialment de literatura juvenil, tres de les quals són de Verne, i de Gemma Redortra (Eumo Editorial, 2006), traductora, a més, d'Anna Frank i d'un títol d'H. G. Wells. Totes quatre versions del Viatge al centre de la Terra han estat publicades en col-leccions o editorials adreçades especialment a lectors joves. L'última, de Redortra, té la particularitat que constitueix la traducció d'un extracte de l'original vernià, adaptada, a més, a un públic aprenent de català, feta a partir de només 3.000 paraules, segons la tècnica de la col-lecció «Català Fàcil» (Eumo Editorial).

Rosa Elias i Cornet era filla de Feliu Elias, conegut per $A p a$, crític, pintor i caricaturista, i alhora era neboda de Gaietà Cornet, caricaturista i dibuixant justament d'Editorial Baguñà. Nascuda a Barcelona el 1913, féu els primers estudis a l'Escola Blanquerna. Gran lectora gràcies a la biblioteca familiar, on molt probablement també trobà Verne i, no cal dir-ho, els productes de la factoria Baguñà, arribà a ser secretària de Francesc Macià entre 1932 i 1933. La família Elias-Cornet s'exilià a França el 1939; la Rosa, a París, i la resta de la família, a Tolosa de Llenguadoc (un germà metge, Jaume, també traductor, amic personal de Màrius Torres, que li dedicà el poema Venus, s'establí a Londres). 


\subsection{Rosa Elias i Rafael Tasis}

L'amistat de Rosa Elias amb Rafael Tasis abans d'exiliar-se i les relacions posteriors de tots dos a l'elixi parisenc, degueren propiciar la tasca de traductora i la tria de Verne. En efecte, Tasis (Barcelona 1906 - París 1966), novel-lista, assagista, crític, divulgador cultural i traductor, era un apassionat de la novel.la històrica i de la d'aventures, d'entre les quals hi havia sens dubte les de Verne, que també trobà a la biblioteca familiar.

Els anys que Tasis col-laborà a La Publicitat (en català, del 1922 al 1939), coneix de primera mà el periodisme d'escriptors com Rovira i Virgili, Pla, Soldevila, Nicolau d'Olwer, Sagarra o Foix, dels quals adopta el model de prosa moderna, natural i flexible, que li serveix per a les traduccions, especialment per al joc de diversos registres novel-lístics tot fugint del noucentisme més encarcarat, com assenyala Coll-Vinent (2007).

Tasis volia eixamplar el públic de la novel.la, fer-ne un producte d'entreteniment, però amb dignitat literària. En un article a Mirador Tasis (1934: 6) assenyalava: «Necessitem que els novel-listes ho facin bé, que tinguin un domini absolut de llur tècnica si volem crear un públic que llegeixi en català, i si volem conservar-lo.» Tasis va predicar amb l'exemple, i el 1959 publicava també a Miquel Arimany Editor una retraducció de les Aventures de Romà Kalbris, d'Héctor Malot, que ell ja havia traduït 36 anys abans (el 1923, a A. Artís). En la retraducció, en transforma l'estil i la llengua tot polint-los, simplificant-los i adequant-los als lectors joves coetanis. Més tard, poc abans de morir (1966) tradueix, per a la col-lecció La Cua de Palla d'Edicions 62, clàssics de la novel.la policíaca, com ara La clau de vidre, 1963, de Dashiell Hammett o Amb la por al cos, 1964, de Margaret Millar.

\section{Fugint DELS CLIXÉS NOUCENTISTES}

La traductora del primer Viatge al centre de la Terra, ja a la postguerra, no es desempallega facilment d'uns quants clixés noucentistes, com ara l'ús dels noms propis de persona sense l'article personal al davant, cosa que també fa Valls en la seva traducció del 1982, però no les versions de Vidal del 2003 o de Redortra del 2006, que sí que anteposen l'article personal al nom dels personatges.

Rosa Elias supera, però, l'estigma noucentista del tractament de vós, i adopta el de $t u$ o el de vostè en els personatges centrals de l'obra, segons el grau de familiaritat que mantenen en la història, tal com fa també la versió de Gemma Redortra. Contràriament, Valls i Vidal se serveixen del vós en el tracte del nebot cap a l'oncle o entre la criada i l'oncle, si bé hi ha coincidència en totes quatre versions del tractament de $t u$ de l'oncle envers el nebot i l'afillada, o bé entre els dos joves. Com a curiositat, s'ha de dir que a Rosa Elias se li escapa el vós dirigit a l'oncle fins al capítol VI. A Vidal i a Valls, al seu torn, se'ls escapa algun vostè dirigit a l'oncle: «Oncle -vaig dir-li-, està ben decidit que marxem?» [Vidal 55] 
I «Vostè mateix.» [Valls 42] 5 . Les traduccions d'Elias i de Valls coincideixen també a decantar-se per l'ús gairebé generalitzat del passat simple en les persones gramaticals altres que la primera del singular, pràctica més pròpia del noucentisme, en lloc del passat perifràstic o compost que utilitzen les versions de Vidal i Redortra, forma més viva i estesa.

Curiosament, la traducció de Vidal (del 2003) és l'única que se serveix de l'arcaisme d'expressar la condició irreal recorrent a l'imperfet. Així, si la primera i l'última de les traduccions, d'Elias i Redortra, respectivament, fan servir «Si esperem fins el 22 de juny, arribarem massa tard» [Elias 38], «Si esperem a sortir el dia 22 de juny no arribarem a l'Snaefels.» [Redortra 18], Valls opta per «Si esperéssim el 22 de juny arribaríem massa tard.» [Valls 48] I, finalment, Vidal s'inclina pel ja esmentat imperfet: «Si esperàvem fins al 22 de juny, arribaríem massa tard.» [Vidal 55].

Valls és potser qui, genèricament, tendeix a triar solucions gramaticals $\mathrm{i}$ lèxiques més arcaiques o apartades de la parla viva, com ara l'ús sovintejat de la passiva morfològica («El sopar fou devorat ràpidament» [Valls 115]). Això no obstant, i pel que fa al lèxic, podem concloure que els tres primers traductors coincideixen a utilitzar un registre literari estàndard, en el sentit d'equidistant entre les solucions més extremament artificials o específiques del llenguatge literari i les que se n'aparten i s'acosten al col-loquialisme. No sembla, d'altra banda, que les retraduccions del Viatge tinguin l'origen en l'envelliment de l'anterior. El fet que en totes hi coincideix allò que he anomenat registre literari estàndard, deu ser responsabilitat, en part, de la voluntat d'instrucció pedagògica de Verne, cosa que li exigeix l'adopció de la funció referencial o informativa del llenguatge per damunt de la funció estètica o poètica, si manllevem la terminologia a Jakobson. Aquest fet és encara més evident en la traducció de Redortra, l'última, per l'objectiu que persegueix la col-lecció en què es publicà la seva versió. Aquesta col-lecció d'Eumo Editorial, adreçada a aprenents de català com a segona llengua, presenta els textos construïts amb un màxim de 3.000 paraules diferents, com ja he dit, les 3.000 més freqüents de l'idioma i, per tant, lliures de tot artifici literari.

També coincideixen totes quatre traduccions a respectar la llargada dels períodes o seqüències oracionals de l'original, que solen ser mitjanes i breus. No en manipulen, doncs, la llargada, com sovint fa el noucentisme, que presenta una tendència irrefrenable a connectar diverses proposicions a fi d'obtenir seqüències sintàctiques extenses, amb nombrosa subordinació. No cal dir que la traducció de Redortra és la que accentua la brevetat de les frases de l'original, atesa la comesa de la col-lecció. És més, nombroses frases de la versió de Redortra, hi són presentades en forma de reducció, com es pot veure en aquests exemples (en negreta hi ha marcades, a més, certes diferències i coincidències lèxiques significatives):

5. La referència entre claudàtors remet a l'original o bé a la versió del traductor que s'hi esmenta i a la pàgina on hi ha la mostra reproduïda del text. 


\begin{tabular}{|c|c|c|c|}
\hline $\begin{array}{l}\text { Redortra } \\
(2006: 46)\end{array}$ & $\begin{array}{l}\text { Valls (1982: 275- } \\
\text { 276) }\end{array}$ & $\begin{array}{l}\text { Vidal (2003: } \\
\text { 297-298) }\end{array}$ & $\begin{array}{l}\text { Elias (1959: 214- } \\
\text { 215) }\end{array}$ \\
\hline $\begin{array}{l}\text { Es coneix a tot } \\
\text { el món. }\end{array}$ & $\begin{array}{l}\text { Els diaris més } \\
\text { famosos es dispu- } \\
\text { taren els principals } \\
\text { episodis. }\end{array}$ & $\begin{array}{l}\text { Els diaris més } \\
\text { acreditats se'n van } \\
\text { disputar els princi- } \\
\text { pals episodis. }\end{array}$ & $\begin{array}{l}\text { Els diaris més } \\
\text { prestigiosos s'apo- } \\
\text { deraren dels princi- } \\
\text { pals episodis. }\end{array}$ \\
\hline $\begin{array}{l}\text { Què va passar } \\
\text { durant el viatge? }\end{array}$ & $\begin{array}{l}\text { Quin fenomen, } \\
\text { però, ha pogut pro- } \\
\text { duir aquest capgira- } \\
\text { ment? }\end{array}$ & $\begin{array}{l}\text { Però quin feno-men } \\
\text { devia produir aquesta } \\
\text { inversió? }\end{array}$ & $\begin{array}{l}\text { Però quin feno-men } \\
\text { ha pogut pro-vocar } \\
\text { aquest cap-girament? }\end{array}$ \\
\hline $\begin{array}{l}\text { Un dia, al des- } \\
\text { patx de l'oncle, } \\
\text { jo em mirava } \\
\text { la brúi-xola. } \\
\text { De sobte, vaig } \\
\text { cridar. }\end{array}$ & $\begin{array}{l}\text { Un dia, arreglant } \\
\text { una col-lecció de } \\
\text { minerals, vaig trobar, } \\
\text { al seu gabinet, } \\
\text { aquella brúixola i em } \\
\text { vaig posar a observar- } \\
\text { la. [...] } \\
\text { Vaig fer un crit } \\
\text { i el professor vingué } \\
\text { corrent. }\end{array}$ & $\begin{array}{l}\text { Un dia, orde- } \\
\text { nant una col-lecció } \\
\text { de minerals al seu } \\
\text { despatx, vaig veure la } \\
\text { famosa brúixola i em } \\
\text { vaig posar a examinar- } \\
\text { la. [...] } \\
\text { Vaig deixar anar } \\
\text { un crit. El professor } \\
\text { va venir corrents. }\end{array}$ & $\begin{array}{l}\text { Un dia, mentre } \\
\text { arranjava una col- } \\
\text { lecció de minerals } \\
\text { en el seu despatx, } \\
\text { vaig veure la famosa } \\
\text { brúi-xola, i me la vaig } \\
\text { quedar mirant una } \\
\text { bona estona. [...] } \\
\text { De sobte vaig fer } \\
\text { un crit de sorpresa. } \\
\text { El professor corre-gué } \\
\text { cap a mi. }\end{array}$ \\
\hline
\end{tabular}

En l'àmbit de la fraseologia i del lèxic en general, no presenten tampoc gaires diferències. Hi ha, això sí, tries personals. L'expressió francesa "Disait le professeur en fronçant le sourcil» [Verne original 24], Elias la resol així: «Digué el professor arrufant el nas» [Elias 13]. Valls, així: «Deia el professor arrugant les celles» [Valls 19]. I Vidal, combinant les dues anteriors: «Deia el professor arrufant les celles.» [Vidal 21]. Trobem un altre exemple en el cas del següent vocatiu. Elias tradueix «Parle, mon garçon» [Verne original 59] per «Parla, home, parla» [Elias 29]; Valls, per «Parla, noi, parla» [Valls 38] i Vidal «Parla, xicot, no te n'estiguis.» [Vidal 42].

En altres aspectes de la traducció hi ha solucions més encertades que d'altres. L'adjectiu méchant de la frase "Otto Lidenbrok neétait pas un méchant homme» [Verne original 8], Valls la transforma en «Otto Lidenbrock [...] no era un home dolent.» [Valls 19]. Vidal, també: «L'Otto Lidenbrock no era pas un home dolent.» [Vidal 10]. Elias ja fa el tomb i diu: «Otto Lidenbrock no era pas un mal home.» [Elias 6] Finalment, la versió de Redorta conclou: «Lidenbrock era un bon home, però un a mica estrany.» [Redortra 9].

Per tancar aquest recorregut ràpid per la diversitat de solucions proposades pels traductors, caldria destacar un cas de desavinença ben curiós. El capítol 10 comença, en la versió original, així: «Le dîner était prêt.» [Verne original 110]. I acaba: «Pendant ce dîner, mon oncle venait d'apprendre des choses importantes.» [Verne original 120] Doncs bé, Elias situa aquest àpat a l'hora de sopar, i Valls, a l'hora de dinar, com Redortra. Vidal, en canvi, comença parlant d'un dinar que transforma, al final, en sopar. És sabut que dîner, en francès, pot fer referència tant al sopar com al dinar (de fet, el context del capítol no aclareix si es tracta de l'àpat del migdia o del vespre). 


\section{Conclusions}

A tall de conclusió caldria destacar un parell o tres d'aspectes. El noucentisme, tot promovent la traducció de literatura universal amb vista a trobar un cànon literari propi que alhora fos el suport del nou model lingüístic que s'estava codificant, va aconseguir-ho en part entre provatures i malencerts. Riba, Carner o Sagarra en foren bons models, com també els textos de la Bernat Metge, o de Mallafrè més tard, per exemple.

Però és la conjunció de l'arribada de Verne, primer traduït a l'espanyol i després al català, amb el desenvolupament de la indústria literària popular adreçada a un públic ampli i heterogeni (és fonamental el paper de l'editor Baguñà amb la revista En Patufet i les altres col-leccions de narrativa), amb la tasca de Josep M. Folch i Torres, seduït per Verne (i també per Dickens), que, sabent manejar el model lingüístic que bastia Fabra, es va aconseguir un model narratiu nou, renovador, especialment en l'àmbit de la literatura juvenil i de masses, mitjançant una llengua coherent, flexible, viva i d'acceptació general, la qual recuperarien a la postguerra, per exemple, les quatre traduccions d'una mateixa obra de Verne, el Viatge al centre de la Terra, encapçalades per les de Rosa Elias.

Verne va servir de model narratiu i alhora ell mateix assolí en català un èxit com ja havia assolit en altres cultures normalitzades, sobretot quan les nostres condicions sociopolítiques ho permeteren. Verne i els productes de la factoria Baguñà van passar a formar part també del bagatge de nombrosos escriptors i traductors, pretèrits i actuals, que abandonaren els aspectes més encarcarats del noucentisme. En aquesta empresa, hi va coadjuvar també la llengua de diversos escriptors/periodistes, com Rovira i Virgili, Nicolau d'Olwer, Pla, Soldevila, Sagarra o Tasis i, sovint, el fet de la presa de consciència que els textos anaven adreçats, o bé al gran públic, o bé a la gent jove quan la llengua del país va poder entrar en l'escola.

Finalment, s'ha de remarcar que les diverses traduccions al català d'una mateixa obra de Verne, com hem vist, no tenen a veure amb el fet que el temps les hagi fet envellir, sinó més aviat les retraduccions són filles probablement del boom editorial, a partir dels anys 80 , que aconsellava tenir a cada catàleg una $\mathrm{o}$ més obres de Verne, garantia d'èxit. 


\section{Bibliografía}

Coll-Vinent Sílvia, "Rafael Tasis, traductor i divulgador literari», Quaderns. Revista de Traducció, no 14, 2007, p. 95-104.

Gregori Soldevila Carme, Pere Calders: tòpics i subversions de la tradició fantàstica, Barcelona, Publicacions de l'Abadia de Montserrat, 2006, 291 p.

Malé Jordi, "Una llengua en plena ebullició.” Els traductors davant el català literari a les primeres dècades del segle XX», Quaderns. Revista de Traducció, no 14, 2007, p. 79-94.

Mallafrè Joaquim, "Models de llengua i traducció catalana», Quaderns. Revista de Traducció, no 5, 2000, p. 9-27.

Molas Joaquim, «Les col-leccions de novel.la curta», Serra d'Or, no 432, abril de 1988, p. 60-65.

Murgades Josep, "Apunt sobre noucentisme i traducció», 1994, Els Marges, no 50, 1994, p. 92-96.

Ortín Marcel, «Las traducciones, del noucentisme a la actualidad» dans Lafarga Francisco, Pegenaute Luis (eds.), Historia de la traducción en España, Salamanca, Ambos Mundos, 2004, p. 674-719.

Parcerisas Francesc, Traducció, edició, ideologia. Aspectes sociològics de les traduccions de La Bíblia $i$ de L'Odissea al català, Vic, Eumo Editorial, 2009, 276 p.

Pérez Vallverdú Eulàlia, «La influència de Jules Verne en la literatura infantil i juvenil de Josep M. Folch i Torres», Serra d'Or, no 543, març de 2005, p. 21-24.

Pericay Xavier, Tutain Ferran, El malentès del noucentisme. Tradició i plagi a la prosa catalana moderna, Barcelona, Proa, 1996, 318 p.

Pinyol i Torrents Ramon, «La recepció de Verne a Catalunya», Serra d’Or, no 543, març de 2005, p. 17-20.

Riera Tuèbols Santiago, «Jules Verne, un científic, un literat o un diletant? », Serra d'Or, no 543, març de 2005, p. 24-27.

Serrafina Nicolau, «H. G. Wells. Novelista inglés dels temps que corren», Pèl \& Ploma, no 89 , gener de 1903, p. 3.

Tasis Rafael, «Falles d'una literatura - Variacions sobre la novel-la», Mirador, no 27, setembre de 1934 , p. 6.

\section{Original i traduccions de Jules Verne analitzades}

Verne Jules, Voyage au centre de la terre, Quebec, La Bibliothèque électronique du Québec, col.1. «À tous les vents» no 14, 2011, 310 p.

- El viatge al centre de la Terra, Barcelona, L'Atzar Edicions, col.l. "Lectures de l'estudiant» no 13, 1982, 276 p. [Traducció de Joan Valls]

-Viatge al centre de la Terra, Barcelona, La Galera, col.l. «El corsari» no 53, 2003, 298 p. [Traducció de Jordi Vidal]

-Viatge al centre de la Terra, Vic/Barcelona, Eumo Editorial / Publicacions i Edicions de la Universitat de Barcelona, col.l. «Català facil» no 7, 2006, 46 p. [Traducció de Gemma Redortra i Vilà]

Verne Juli, Viatge al centre de la Terra, Barcelona, Miquel Arimany Editor, col.l. «Sant Jordi» no 3, 1959, 215 p. [Traducció de Rosa Elias] 